\title{
A Role for Caspase-1 in Serum Withdrawal-Induced Apoptosis of Endothelial Cells
}

\author{
Andrea R. King, Sheila E. Francis, Collette J. Bridgeman, Helen Bird, \\ Moira K. B. Whyte, and David C. Crossman \\ Cardiovascular Research Group (ARK, SEF, CJB, HB, DCC), Division of Clinical Sciences (North), Clinical Sciences \\ Centre, University of Sheffield, Northern General Hospital, and Academic Unit of Respiratory Medicine (MKBW), \\ Division of Genomic Medicine, Royal Hallamshire Hospital, Sheffield, United Kingdom
}

\begin{abstract}
SUMMARY: Mouse lung endothelial cells (MLEC) and HUVEC were used under serum withdrawal (SW) conditions as a model of endothelial cell (EC) apoptosis. Apoptosis was quantified by time-lapse video microscopy. Mouse lung ECs from caspase-1 ${ }^{-1-}$ mice had significantly reduced rates of SW-induced apoptosis compared with wild-type mice, specifically implicating caspase-1 in proapoptotic signaling in ECs. SW conditions induced HUVEC apoptosis with concomitant activation of caspase-1. Further studies demonstrated that the caspase-1 inhibitors z-VAD and z-YVAD significantly reduced the rate of SW-induced HUVEC apoptosis. HUVEC, when transfected with caspase-1, showed a highly significant increase in apoptosis. SW was associated with increases in reactive oxygen species production that were significantly inhibited by the antioxidant $\mathrm{N}$-acetyl-L-cysteine, although rates of apoptosis and caspase- 1 activation were unaffected. These results demonstrate the involvement of caspase-1 in SW-induced EC apoptosis, independently of reactive oxygen species production. (Lab Invest 2003, 83:1497-1508).
\end{abstract}

$A$ poptosis, the process of innate cellular death, is an accepted part of cell biology. The cellular mechanisms of apoptosis are complex and diverse, with considerable cell-type specificity.

The activation of intracellular cysteine proteases (caspases) that have a unique cleavage site involving an aspartate residue is crucial to the process of apoptosis (Whyte, 1996; Wolf and Green, 1999). Once activated, caspases cleave cellular substrates, leading to characteristic morphologic hallmarks of apoptosis (Nicholson and Thornberry, 1997). There is a "hierarchy" of caspases in the control of apoptosis, with regulatory caspases (eg, caspase-2, -8, -9, and -10), which have long prodomains, initiating cleavage of downstream executioner caspases (eg, caspase-3, -6, and -7). The prototypic caspase, caspase-1, however, was originally identified as the enzyme responsible for processing IL-1 $\beta$ to its $17-\mathrm{kDa}$ mature form (Cerretti et al, 1992). Overexpression of caspase-1, as with most other caspases, produces apoptosis (Miura et al, 1993). However, caspase-1 is not generally regarded as a component of the cell death machinery; together with caspases- 4 and -5 , it is regarded as an "inflam-

\section{DOI: 10.1097/01.LAB.0000093096.62765.85}

Received June 19, 2003.

This work was supported by a British Heart Foundation project grant, Wellcome Trust project grant no. 053841, and a small research grant from the Northern General Hospital.

Address reprint requests to: Dr. A. R. King, Cardiovascular Research Group, Division of Clinical Sciences (North), Clinical Sciences Centre, University of Sheffield, Northern General Hospital, Herries Road, Sheffield S5 7AU, UK. E-mail: a.r.king@sheffield.ac.uk matory caspase" that functions only in cytokine processing (Martinon et al, 2002; Wolf and Green, 1999).

The vascular endothelium has a central role in inflammation, the response to infection, and the pathogenesis of vascular disease. Endothelial cells (EC) can be induced to undergo apoptosis by a number of treatments, including TNF- $\alpha$ in the presence of protein synthesis inhibitors (Polunovsky et al, 1994), radiation (Haimovitz-Freidman et al, 1994), certain snake venoms (Araki et al, 1993), lipopolysaccharide (LPS) (Choi et al, 1998), and oxidized low-density lipoprotein (Harada-Shiba et al, 1998; Sata and Walsh, 1998). EC apoptosis occurs as a widespread event in thrombotic thrombocytopenic purpura (Laurence et al, 1996) and may occur in systemic sclerosis induced by anti-EC antibodies (Bordron et al, 1998; Sgonc et al, 1996). EC apoptosis may occur in a focal manner in atherosclerosis (Tricot et al, 2000), and EC apoptosis in culture can be induced by the addition of plasma from patients with unstable coronary syndromes (Chen et al, 2003). Growth factor withdrawal of ECs, for which the in vitro model is culture in low or absent serum, leads to apoptosis via caspase- 3 activation (Levkau et al, 1998).

Serum withdrawal (SW) is also known to induce oxidative stress in cells, demonstrated by an excess production of reactive oxygen species (ROS), such as superoxide anion $\mathrm{O}_{2}-, \mathrm{H}_{2} \mathrm{O}_{2}$, hydroxyl radical $\mathrm{OH}$, and organic peroxides that can be inhibited by intracellular antioxidants (Greenlund et al, 1995). Mild oxidative stress is one mechanism involved in the induction of apoptosis and can damage cells by lipid peroxidation and alteration of protein and nucleic acid structure (Slater et al, 1996; Suzuki et al, 1997). ROS 
have been shown to be responsible for the inducible expression of genes involved in inflammatory and immune responses (Schreck et al, 1991). Recent data suggest that caspase-1 may have a hitherto unsuspected role in the regulation of apoptosis. Both Salmonella and Shigella are able to kill myeloid cells via generation of specific activators of caspase-1 (Hersh et al, 1999; Hilbi et al, 1998), and caspase-1 has been implicated in acinar cell death in experimental pancreatitis. We have recently demonstrated a role for caspase-1 in the constitutive apoptosis of neutrophils (Rowe et al, 2002). These data are of particular relevance to ECs, because they generate IL-1 $\beta$ (Schumann et al, 1998) and must contain activated caspase-1, if active IL-1 $\beta$ is produced (Li et al, 1995). In addition, LPS, which activates caspase-1 (Martinon et al, 2002), is known to accelerate EC apoptosis. There is, therefore, the potential for caspase-1 to participate in the induction of apoptosis in these cells.

ECs from caspase-1 ${ }^{-/-}$mice were used to demonstrate a direct role for caspase-1 in EC apoptosis after SW. Our findings were confirmed by demonstration of caspase-1 activity in HUVEC after SW, with specific caspase-1 inhibitors abrogating cell death in HUVEC and human saphenous vein endothelial cells (HSVEC). We also show that the proapoptotic action of caspase- 1 is independent of ROS generation.

\section{Results}

\section{SW-Induced Apoptosis in Caspase-1-1- and Wild-Type Mouse Lung Endothelial Cells (MLEC)}

Figure 1A (inset) indicates typical FACS profiles for E-selectin cell surface expression in caspase-1-1MLEC, with a significant shift seen in the FACS profile after cytokine stimulation [caspase- $1^{-/-}$median shift fluorescence values: control (no primary antibody) $=$ 2.57, $-\mathrm{TNF}-\alpha=6.44$, $+\mathrm{TNF}-\alpha=15.54$ arbitrary fluorescence units], thus demonstrating an EC phenotype of the isolated cells. MLEC cultures were more than $99 \%$ pure as assessed by histologic staining for von Willebrand factor and/or platelet-endothelial cell adhesion molecule- 1 and counting positive cells per field/total cells per field $\times 100$.

MLEC were subjected to SW, and apoptosis was detected and quantified by time-lapse video microscopy (TLVM) (McCarthy et al, 1997) on the basis of rate of development of cell shrinkage, membrane blebbing, and detachment during 48 hours. As expected, only a proportion of cells underwent apoptosis. A representative graph is shown Figure 1A. There was a significant difference in the susceptibility of caspase-1 $1^{-1-}$ MLEC to SW compared with wild-type cells: caspase-1/-, $6.06 \pm 2.3 \%$; SW, wild-type $21.72 \pm 0.99 \%$ apoptosis at 48 hours $(n=3, p=$ 0.001 ). In addition, there was a tendency for a delay in the onset of apoptosis, ie, the time to first apoptotic event: caspase-1 $1^{-1-} 7.36 \pm 3.40$ hours; SW, wild-type $1.01 \pm 0.16$ hours $(n=3)$, but this failed to reach statistical significance.

In contrast, staurosporine $(2 \mu \mathrm{mol} / \mathrm{L})$ induced apoptosis in MLEC from caspase- $1^{-/-}$and wild-type
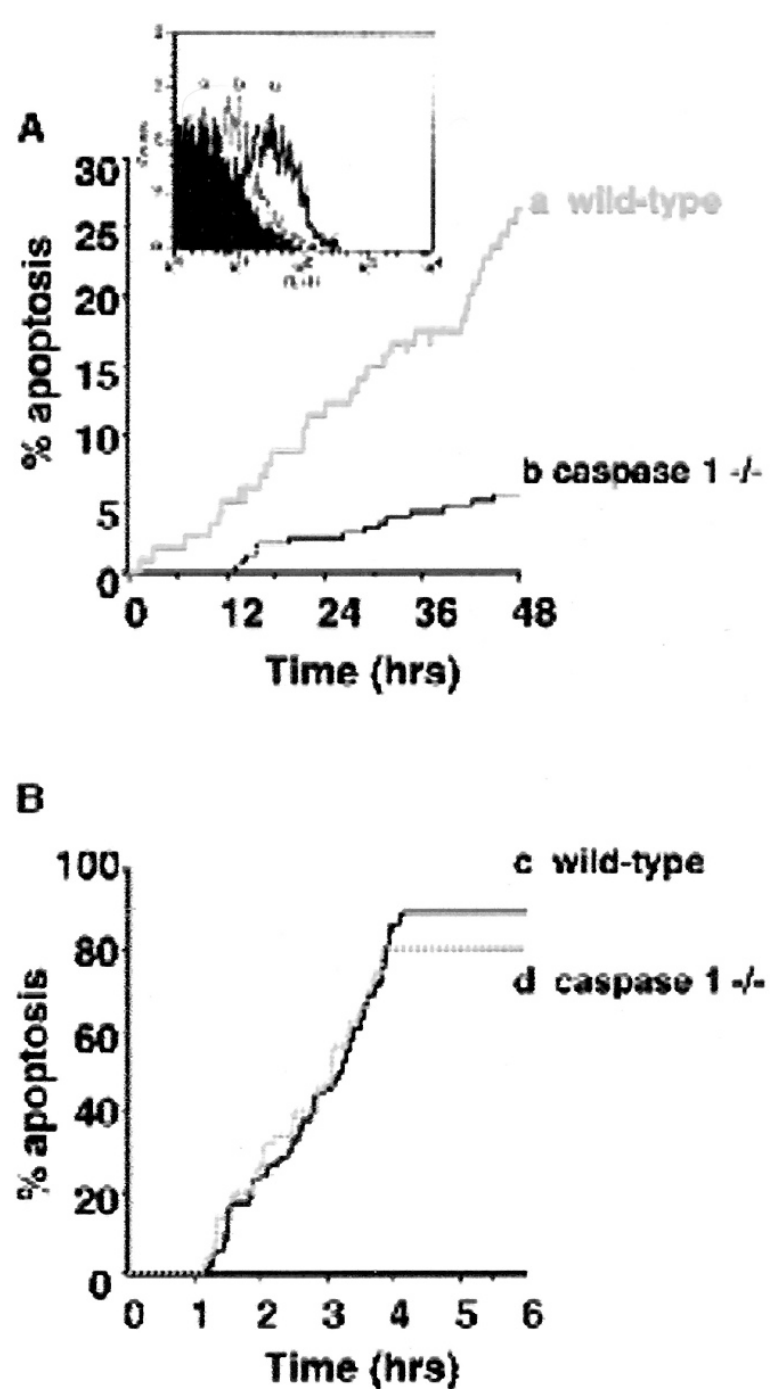

Figure 1.

Caspase-1-1- mouse lung endothelial cells (MLECs) are resistant to serum withdrawal (SW)-induced apoptosis but undergo apoptosis at similar rates in response to staurosporine $(2 \mu \mathrm{mol} / \mathrm{L})$ compared with wild type MLEC. Cumulative MLEC deaths were assessed by time-lapse video microscopy (TLVM) from caspase $1^{-1-}$ mice and wild-type mice. A, Graph, line $a$, wild-type MLEC in the presence of SW; line $b$, caspase $1^{-1-}\left(\left(\mathrm{ICE}^{-/-}\right)\right.$in the presence of SW. Inset, FACS profiles of unstimulated and stimulated caspase$1^{-1-}$ MLEC: (a) no primary antibody; (b) MLEC without TNF- $\alpha$; (c) MLEC with TNF- $\alpha$. B, MLEC from wild-type and caspase $1^{-1-}$ mice treated with staurosporine $(2 \mu \mathrm{mol} / \mathrm{L})$ : line $c$, wild-type; line $d$, caspase $1^{-1-}$ MLEC.

mice at similar rates in both cell types (Fig. 1B), indicating that these cells could respond equivalently to a stimulus directly activating caspase-3 (Jacobson et al, 1996).

\section{SW Induces HUVEC Apoptosis}

HUVEC were subjected to SW and analyzed by TLVM. As with MLEC, SW induced apoptosis in only a proportion of HUVEC: complete growth medium $(\mathrm{CGM})=13.39 \pm 0.96 \%, \mathrm{SW}=51.17 \pm 1.77 \%$ (apoptosis at 48 hours), $n=3$ independent HUVEC cultures, $p<0.01$. The first morphologic changes were observed 2 to 4 hours after the onset of SW and became more apparent throughout the SW time 
course (Fig. 2A). Apoptosis was confirmed by demonstration of DNA laddering (Fig. 2B). Trypan blue staining was performed at 24 hours of SW to compare viability between detached cells and those remaining adherent: attached cells $=86 \%$ viable, detached cells $=0 \%$ viable.

\section{Rescue of SW-Induced HUVEC Apoptosis}

HUVEC cultured under SW conditions for 6 hours and then replaced with fresh serum-free medium showed, as expected, similar rates of apoptosis to those described above. HUVEC exposed to SW for 6 hours and then re-fed with CGM (10\% FCS, 10\% NBCS, 20 $\mu \mathrm{g} / \mathrm{ml}$ ECGS, $90 \mu \mathrm{g} / \mathrm{ml}$ heparin) were completely rescued from apoptosis (Fig. 3). Addition of single growth factors at this time point produced a variable response: ECGS $(20 \mu \mathrm{g} / \mathrm{ml})$ was unable to rescue cells, whereas insulin-like growth factor-I (IGF-I) (100

A
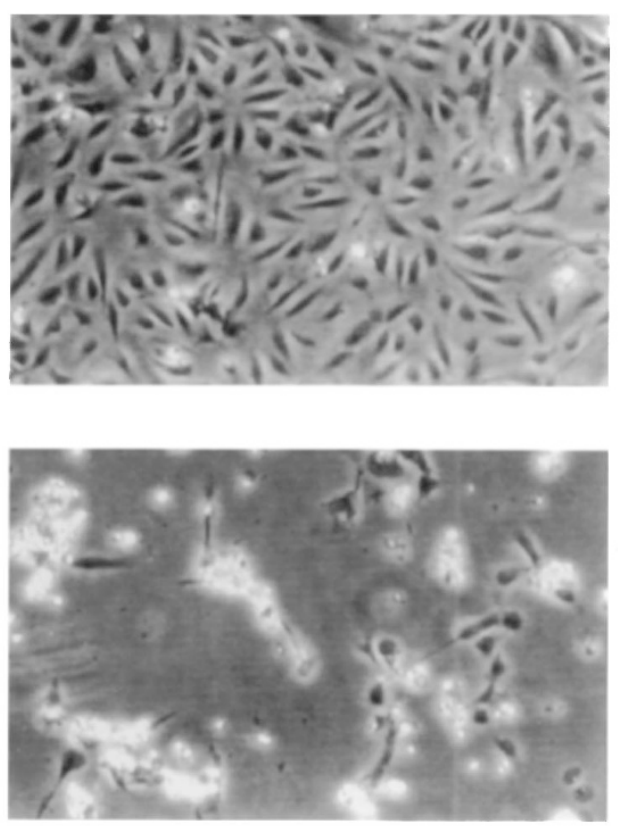

II

B

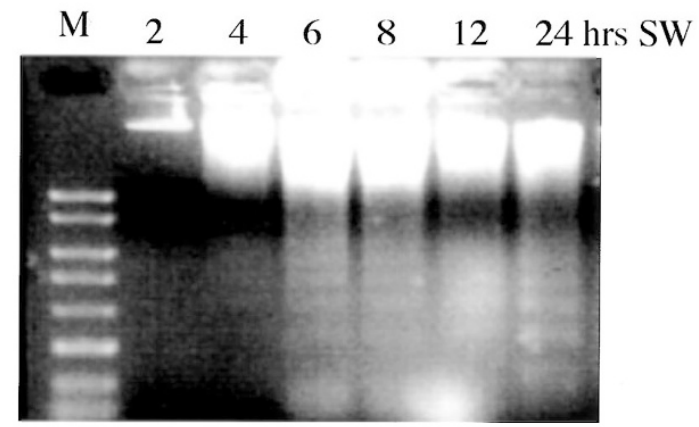

Figure 2.

SW induces changes characteristic of apoptosis assessed by TLVM and DNA fragmentation analysis. A, Both panels show a single frame after 48 hours of filming in a representative experiment. I shows HUVEC in complete growth medium (CGM) and II shows HUVEC exposed to SW. Characteristic changes of cell shrinkage and detachment are easily identifiable. B, Demonstration of DNA laddering consistent with apoptosis. DNA was isolated at the indicated times of SW from detached cells collected from culture medium.
Rescue from SW

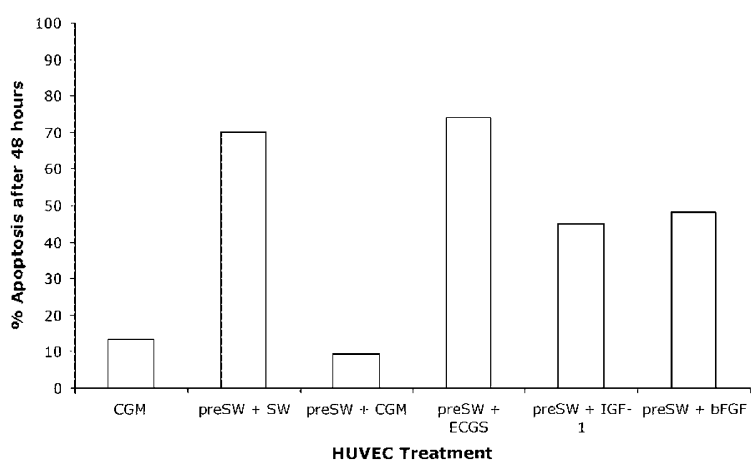

Figure 3.

Rescue of HUVEC induced to undergo SW-induced apoptosis. HUVEC were preincubated under SW for 6 hours before the indicated treatments and TLVM analysis. CGM components were $10 \%$ fetal calf serum (FCS), 10\% newborn calf serum (NBCS), $90 \mu \mathrm{g} / \mathrm{ml}$ heparin, and $20 \mu \mathrm{g} / \mathrm{ml}$ endothelial cell growth supplement (ECGS). Insulin-like growth factor-1 and basic fibroblast growth factor were used at $100 \mathrm{ng} / \mathrm{ml}$, and ECGS was used at $20 \mu \mathrm{g} / \mathrm{ml}$. CGM = control HUVEC maintained in CGM for preincubation and TLVM filming $(n=2)$.

$\mathrm{ng} / \mathrm{ml}$ ) and basic fibroblast growth factor (bFGF) (100 $\mathrm{ng} / \mathrm{ml}$ ) partially rescued cells from SW-induced apoptosis (Fig. 3) $(n=2)$.

\section{SW-Induced HUVEC Apoptosis Is Associated with Caspase-1 Processing}

Western analysis of HUVEC $(n=4)$ showed a gradual reduction in p45 pro-caspase-1 in response to SW during 24 hours. As previously reported, this antibody also cross-reacts with a prominent $50-\mathrm{kDa}$ protein $(\mathrm{Li}$ et al, 1995). In parallel, there was an increase in p20 caspase-1 during the same period of SW, consistent with activation and processing of caspase-1 (Fig. 4A).

Caspase-3 proenzyme expression levels were unchanged after SW, as assessed by Western blot. The 17-kDa processed form was not detected (Fig. 4B).

\section{Caspase-1 Activity in SW-Treated HUVEC}

Caspase-1 activation in SW-induced apoptosis of HUVEC was examined using specific assays based upon cleavage of a fluorescent substrate. Substrate specificity was demonstrated by the inclusion of specific caspase inhibitors that resulted in a reduction of the substrate fluorescent signal. SW induced an increase in caspase- 1 activity in HUVEC that was maximal at 2 hours and had declined to near basal activity by 6 hours. The increase in caspase- 1 activity was inhibited by $z-V A D(100 \mu \mathrm{mol} / \mathrm{L})$. At 2 hours after SW, caspase- 1 activity was $160.3 \pm 22.5 \%$ of the activity at 0 hours $(n=3 ; p=0.065$ comparing basal with 2 hours absolute activity) and was significantly inhibited by z-YVAD $(10 \mu \mathrm{mol} / \mathrm{L})(p=0.004, n=3)$. LPSstimulated THP-1 cells were used as a positive control for the assay because these cells constitutively produce active caspase-1. Caspase-1 activity in LPStreated THP-1 was increased by 2 hours after stimulation and was maximal at 4 hours, returning to basal levels by 6 hours. 
$\mathbf{A}$

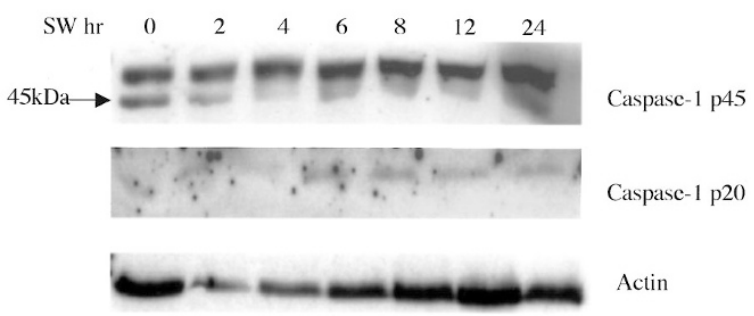

B

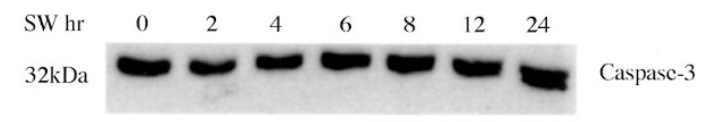

$43 \mathrm{kDa}$

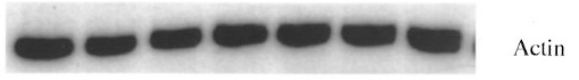

Figure 4

HUVEC exposed to SW activate caspase-1. A, Western blots of HUVEC exposed to SW for the times shown. The $45-\mathrm{kDa}$ band represents $\mathrm{p} 45$ (unprocessed) caspase- 1 , and the $20-\mathrm{kDa}$ bands represent p20 (processed) caspase-1. The blot shown is representative of four separate experiments. $B$, Western blot analysis for caspase- 3 expression. The band shown represents p32 unprocessed caspase-3. Actin is shown as a control for protein loading.

\section{Effects of Caspase Inhibition Upon SW-Induced Apoptosis in HUVEC}

Caspase inhibitors were classified as previously described (Garcia-Calvo et al, 1998). We used TLVM analysis to compare the efficacy of these peptides on inhibition of SW-induced HUVEC apoptosis. Replicate cultures were incubated under SW conditions with or without the addition of the caspase inhibitors $z-V A D$ (nonselective caspase inhibitor) at a concentration of 100 $\mu \mathrm{mol} / \mathrm{L}$ and $\mathrm{z}-\mathrm{YVAD}$ (a group I caspase inhibitor) at 10 $\mu \mathrm{mol} / \mathrm{L}$ at the start of SW. These concentrations were shown to inhibit caspase-1 appropriately in fluorescent substrate assays (see above). The addition of z-VAD at the start of SW significantly decreased the rate of apoptosis, as did the addition of z-YVAD: SW $=57.05 \pm$ $4.07 \%, S W+z-V A D=28.95 \pm 4.3 \%$ (\% apoptosis at
48 hours; $n=3, p=<0.01)$; SW $=59.22 \pm 1.76 \%$, SW $+z-Y V A D=35.28 \pm 4.16 \%$ (\% apoptosis at 48 hours; $n=3, p=<0.01)(n=3$ represents ECs obtained from three independent isolates).

\section{Caspase-1 Processing and Effects of Inhibition Upon SW-Induced Apoptosis in HSVEC}

The above findings were verified in HSVEC, a more differentiated EC type. Replicate cultures were incubated under SW conditions with and without the addition of Z-YVAD $(10 \mu \mathrm{mol} / \mathrm{L})$ at the start of $S W$ and filmed for 48 hours. Addition of Z-YVAD reduced the rate of apoptosis: $S W=79.4 \pm 8.73 \%, S W+z-Y V A D$ $=60.73 \pm 7.69 \%, n=3$ (Fig. 5). Similar findings were also obtained with human lung microvascular endothelial cells (data not shown).

\section{Overexpression of Caspase-1 Induces Apoptosis in HUVEC}

Induction of apoptosis was assessed in fluorescent ECs transfected with enhanced green fluorescent protein.caspase-1 plasmid (pEGFP.caspase-1) compared with cells transfected with pEGFP alone. Transfection efficiency was between $2 \%$ and $7 \%$, which is typical for ECs. At 48 hours, green fluorescent cells showing clear morphologic features of apoptosis were significantly increased in the caspase-1-transfected cells: pEGFP.caspase-1, $93.9 \pm 5.8 \%$; pEGFP, $10.3 \pm$ $2.2 \%$ fluorescent apoptotic cells, $n=5, p<0.00001$ (Fig. 6A). The same plasmid, when transfected into HeLa cells, showed increased caspase- 1 protein expression by Western blot analysis, demonstrating specificity of both the caspase- 1 antibody used in this study and the plasmid (Fig. 6B). THP-1 cells stimulated with PMA and LPS are a recognized positive control for caspase-1. Figure 6B also shows that the transfected caspase-1 band is the same size as endogenously expressed caspase- 1 .

\section{IL-1 $\beta$ and IL-18 Expression in HUVEC and MLEC}

IL-1 $\beta$ and IL-18 are recognized caspase-1 substrates (Ghayur et al, 1997; Gu et al, 1997; Yuan et al, 1993).

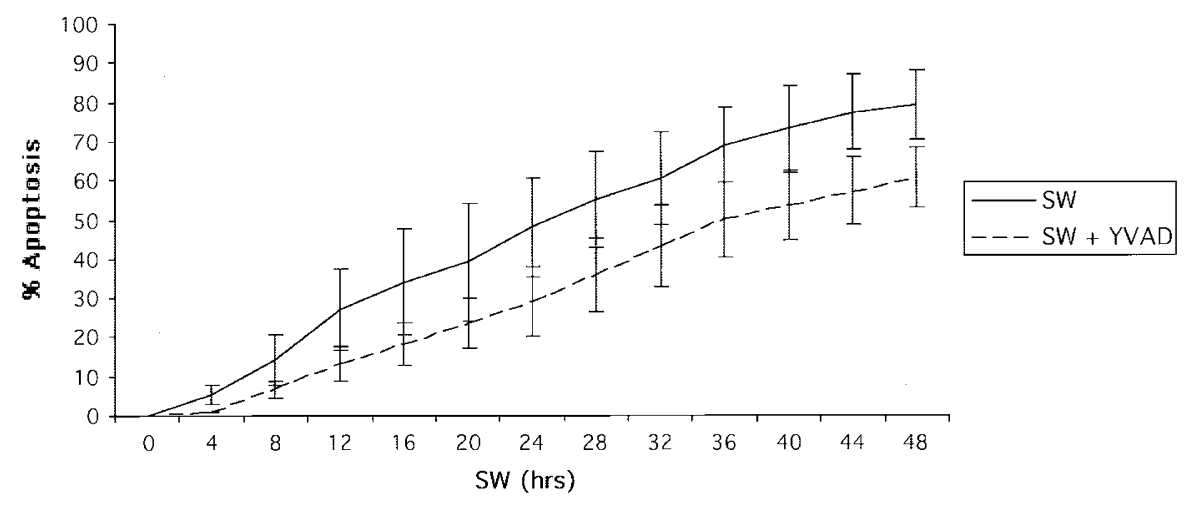

Figure 5.

Inhibition of SW-induced apoptosis in human saphenous vein endothelial cells (HSVEC) by z-YVAD. Graph shown is the result of three separate experiments and shows cumulative percent of apoptosis assessed by TLVM during a 48-hour period. z-YVAD was used at $10 \mu \mathrm{mol} / \mathrm{L}$. 
$\mathbf{A}$

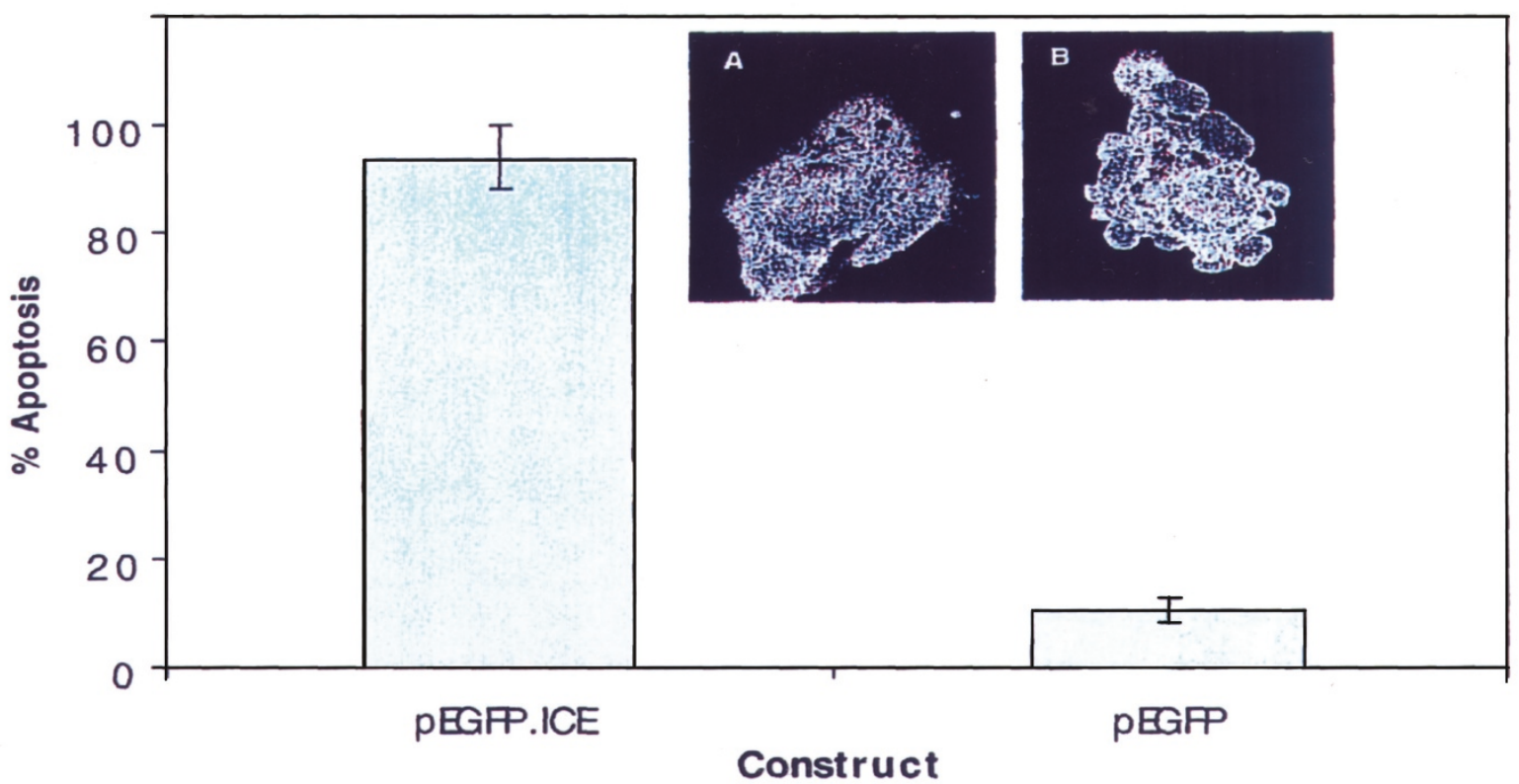

B
1
2
3
4
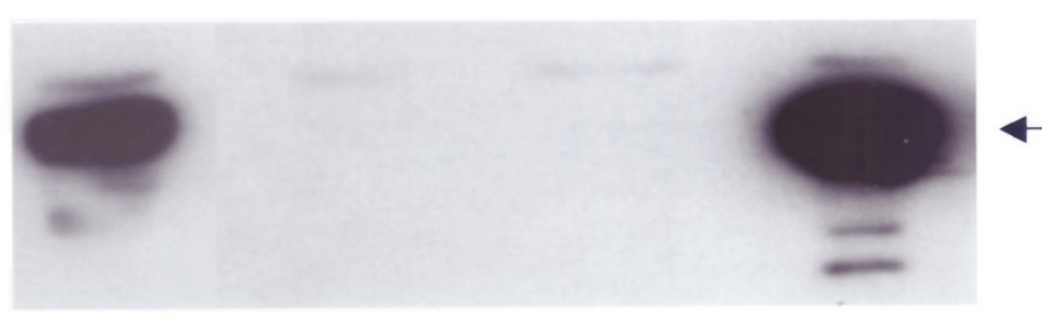

P45 Caspase- 1

Figure 6.

Caspase-1 overexpression in HUVEC induces apoptosis. A, HUVEC were transfected with caspase-1 with GFP (pEGFP.ICE) or GFP alone (pEGFP). Apoptosis was easily assessed by morphologic criteria. The insets show a GFP-positive normal HUVEC and an apoptotic caspase-1/GFP-positive cell. The difference in apoptosis is highly significant $(p<0.00001)$. B, Western blot analysis for caspase-1 in caspase-1 transfected HeLa cells. Lane 1, stimulated THP-1; lane 2, untransfected HeLa; lane 3, pEGFP transfected HeLa; lane 4, pEGFP.ICE transfected HeLa.

Thus, in our model system in which caspase-1 is present and active, the expression and activation status of these substrates was investigated. However, Western blot analysis of HUVEC and MLEC protein isolated from varying SW time points, showed that $\mathrm{IL}-1 \beta$ and IL-18 were undetectable in both their precursor and processed forms using this type of analysis. Positive controls were included to demonstrate specificity and reactivity of the antibodies used: IL-1 $\beta$, purified from bacterial lysates (Santa Cruz-4139 WB); recombinant human IL-18 (R\&D systems B003-5). Actin was used as a loading control to demonstrate protein loading on the gel (data not shown).

\section{ROS Production and Inhibition in HUVEC SW-Induced Apoptosis}

ROS production was detectable within 1 hour of SW and was completely inhibited by $25 \mathrm{~mm} \mathrm{~N}$-acetyl-L-cysteine (NAC) (Fig. 7A). ROS production continued during a 24-hour SW period and was significantly inhibited by 25 mm NAC ( $n=3$; Fig. 7A). Although there was significant inhibition of ROS, $25 \mathrm{~mm}$ NAC had no effect on the rates of SW-induced apoptosis as assessed by TLVM $(n=3$; Fig. $7 \mathrm{~B})$ : $\mathrm{SW}=49.7 \pm 4.08 \%$; $\mathrm{SW}+\mathrm{NAC}=46.83 \pm$ $7.77 \%$ apoptosis at 24 hours.

\section{Effect of NAC on Caspase-1 Activity}

As demonstrated below, caspase-1 activity increased with the onset of SW, gradually returning to baseline levels at 6 hours (Fig. 8). This activity was inhibited by the caspase-1 inhibitor z-YVAD. Figure 8 also shows that NAC (25 mm) had no effect on the increase of caspase-1 activity in response to SW as determined by caspase- 1 fluorogenic activity assays. Thus, although SW induces ROS production in ECs, this does not influence either caspase-1 activity or the onset of apoptosis.

\section{Discussion}

These studies examined whether caspase- 1 has a role in SW-induced EC apoptosis, in which its action may 


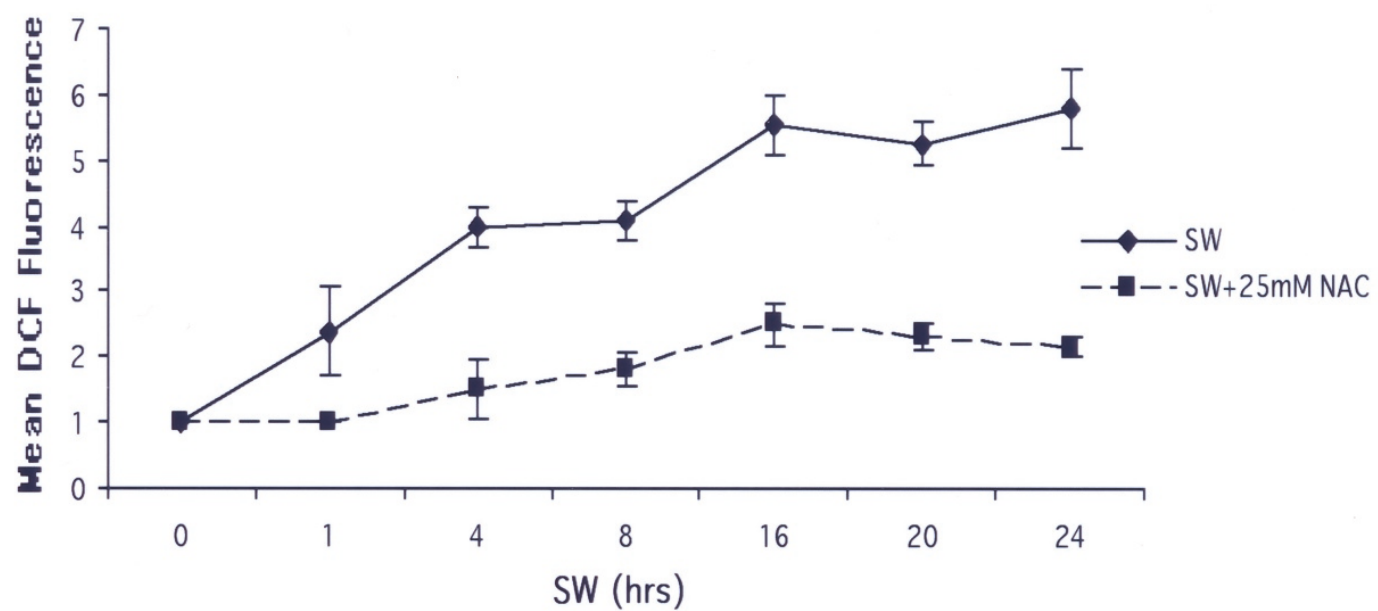

B

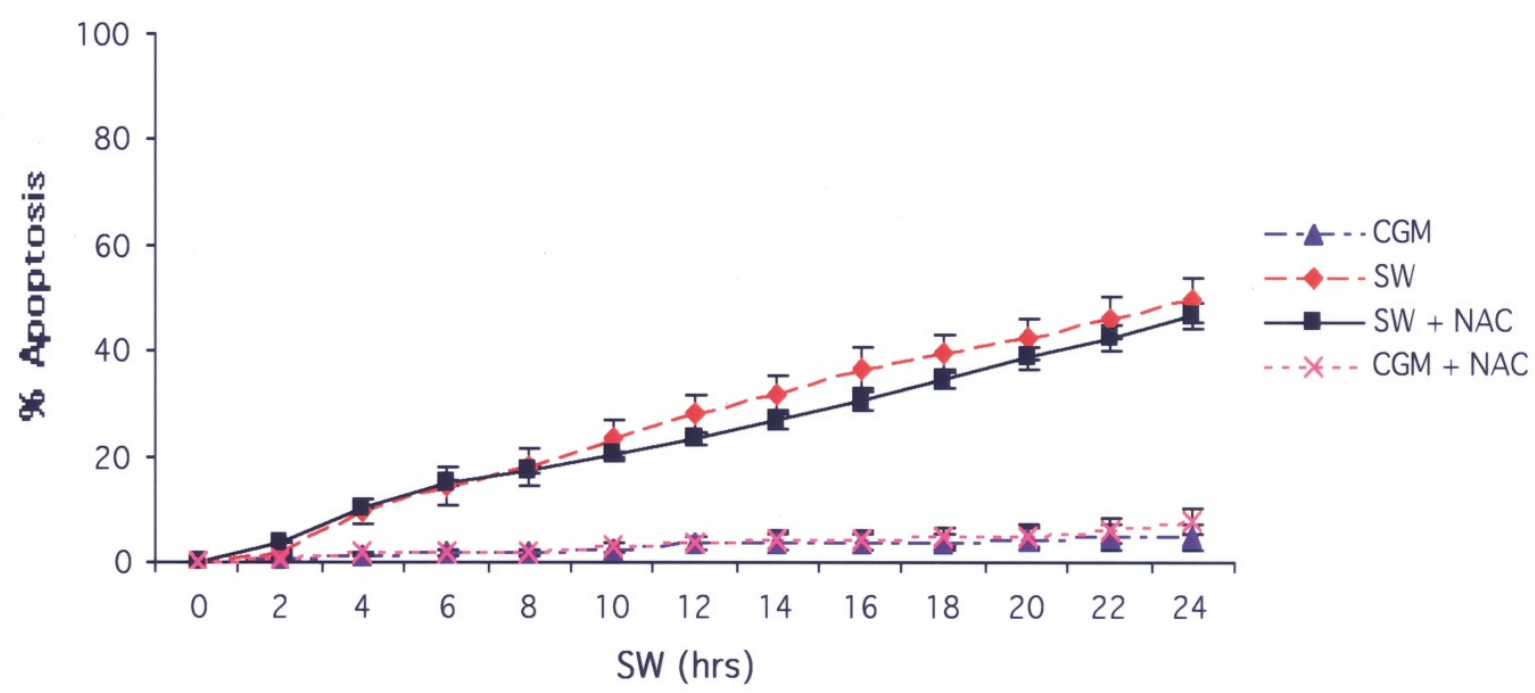

Figure 7.

Reactive oxygen species (ROS) production during SW is inhibited by N-acetyl-L-cysteine (NAC), but rates of apoptosis are unaffected. A, Mean 2',7'dichlorofluorescein fluorescence as assessed by FACS reflects the level of intracellular ROS generation with and without 25 mM NAC during a 6 -hour SW period ( $n$ $=3$ ). B, Cumulative percent of apoptosis during a 24-hour SW time period as assessed by TLVM in SW or CGM with or without 25 mM NAC ( $n=3$ ).

be part of the upstream regulatory caspase pathway, and to determine whether ROS production is a mechanism of caspase-1 activation. Although the central role of caspases in regulation of apoptosis is well established (Whyte, 1996; Wolf and Green, 1999), there has been considerable debate about whether the role of caspase- 1 is confined to cytokine processing or whether it can, in certain circumstances, also regulate apoptosis. Caspase- 1 knockout mice have a minimal apoptosis-deranged phenotype (Kuida et al, 1995; Li et al, 1995) but do show impaired Fasmediated killing of thymocytes (Enari et al, 1996; Kuida et al, 1995) and delayed neutrophil apoptosis (Rowe et al, 2002). However, both apoptotic and antiapoptotic mechanisms are characterized by considerable redundancy, and a number of other apoptosis gene-deleted mice have little in way of an apoptosis-deranged phenotype (Kuida et al, 1996). Further data have implicated caspase- 1 as the target for specific activators of apoptosis generated by bacteria (Hersh et al, 1999; Hilbi et al, 1998). Huntington's disease is associated with caspase- 1 activation in the brain of patients, and in an animal model of Huntington's, overexpression of dominant negative caspase-1 prolongs survival (Ona et al, 1999). Moreover, evidence from other models of apoptosis has identified active caspase-1, where it may function as an upstream regulatory caspase (Marsden et al, 2002).

The role of caspase-1 in EC apoptosis has not previously been studied. However, there is evidence that human ECs express caspase- 1 and its activity can be modulated by recombinant human CD40L (Schonbeck et al, 1997) and that ECs can synthesize and release IL-1 $\beta$ under certain conditions (Schumann et al, 1998; Schonbeck et al, 1997). Moreover, LPS both accelerates EC apoptosis (Choi et al, 1998) and is known to induce caspase-1 (Martinon et al, 2002). The results presented here demonstrate a role for 


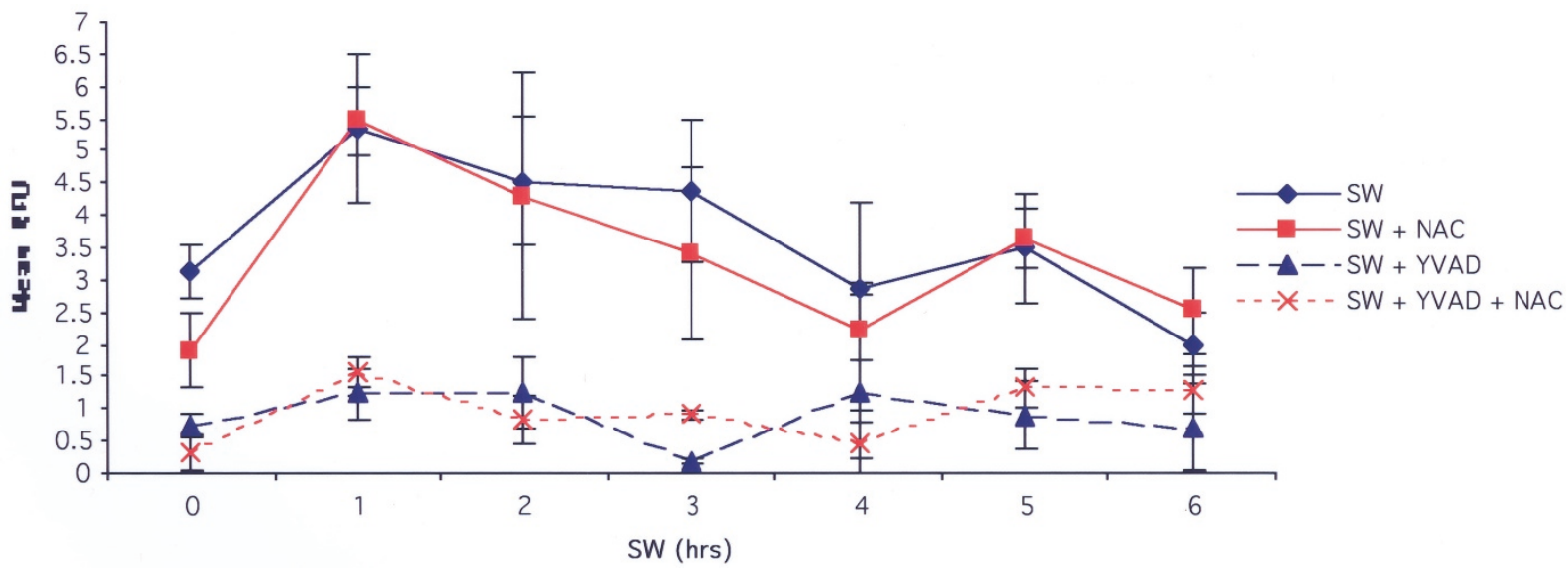

Figure 8.

Caspase-1 activity is unaffected by ROS inhibition. Figure shows $n=3$ experiments in which mean RFU (relative fluorescence units) represents caspase-1 activity at the indicated time points of SW in the presence or absence of $25 \mathrm{~mm}$ NAC with or without the caspase-1 inhibitor Ac-YVAD-CHO.

caspase-1 in SW-induced apoptosis in MLEC, HUVEC, and HSVEC. SW induces ROS activation but this does not seem to be involved either with the induction of apoptosis or the activation of caspase-1.

\section{SW-Induced EC Apoptosis}

In MLEC purified from caspase-1-1- mice, SWinduced apoptosis was significantly delayed at 48 hours compared with wild-type controls. The experiments performed with staurosporine in MLEC from caspase $-1^{-1-}$ mice indicate that the delay in the onset of SW-induced apoptosis does not arise because of a nonspecific defect of EC apoptosis in these mice. Furthermore, the caspase-1 ${ }^{-1-}$ mice used here were the same as those described by Li et al (1995) who showed normal apoptotic responses in a wide variety of cell types to a number of different apoptotic stimuli. These results give persuasive evidence for a role for caspase-1 in the normal signaling of apoptosis in response to SW in the EC. The delay in the onset of apoptosis could be a result of redundant caspases becoming activated by alternative mechanisms from those normally involved in activating caspase-1.

The morphologic changes seen under SW conditions in HUVEC were consistent with those observed in MLEC undergoing SW-induced apoptosis. The slightly different rates of apoptosis (\% apoptosis at 48 hours) for these cells compared with MLEC could have arisen for a number of reasons, most notably differences in the vascular bed of origin and the species of origin.

The appearance of a DNA ladder from HUVEC exposed to SW confirms that the observed cell death occurred via apoptosis. The ladder pattern was detectable 4 hours after SW, consistent with the first morphologic changes observed by TLVM. DNA fragmentation analysis was performed on cells that had become detached from the culture flask. Trypan blue exclusion assay confirmed that these cells were dead.

A number of supplementary factors working in cohort seem to be required to rescue cells from SW- induced apoptosis, because rescue was not observed with ECGS alone and because only partial rescue was observed with IGF-1 and bFGF, even at concentrations higher than would normally be used for supplementing growth media (Dunham and Koch, 1998; Saltau and McLaughlin, 1993). Addition of all CGM components, however, successfully rescued cells from undergoing SW-induced apoptosis.

\section{SW-Induced Apoptosis and Caspase-1 Activation}

SW induces EC apoptosis with evidence of caspase-1 processing to its active form. Western blotting confirmed the appearance of the active p20 caspase- 1 subunit between 2 and 6 hours of SW, which remains elevated for several hours and returns to baseline levels by 24 hours. Additionally, the fluorogenic assays also show that caspase- 1 activation occurs within the first 2 hours of SW and precedes the morphologic changes of apoptosis, as seen by TLVM. However, the fluorogenic assay demonstrated a return to basal activity by 6 hours. The temporal separation of the fluorogenic and Western assessments of caspase-1 activity may arise for a number of reasons. One of these may be depletion of the fluorogenic substrate. Early activation in a functional assay might also be expected to significantly precede changes detected by Western blotting, which takes time for sufficient processed protein to accumulate and in which protein remains detectable for a longer period of time. A nonspecific $50-\mathrm{kDa}$ protein that cross-reacts with anti-caspase- 1 has been reported previously ( $\mathrm{Li}$ et al, 1995; Lin et al, 2000) and has been detected in mouse macrophages, NIH 3T3 fibroblasts, and HT-29 cells. As also noted by Li et al (1995), we failed to diminish this band by preclearing the whole cell lysates. Its identity thus remains uncertain.

The caspase- 1 activation data support a caspase1-dependent mechanism in the upstream signaling of $\mathrm{SW}$-induced apoptosis. This is further supported by the use of caspase inhibitors. The inhibitory profile of z-VAD is wide, but the data with z-YVAD (a group I 
caspase inhibitor) are consistent with the involvement of a caspase-1 family member. It has been reported that z-YVAD is without inhibitory effect on downstream caspases (Dai and Krantz, 1999; Margolin et al, 1997). Induction of apoptosis in HUVEC overexpressing caspase- 1 reemphasizes the ability of this caspase to act as a death-mediating protease in nontransformed cells (Miura et al, 1993).

Because EC susceptibility to apoptosis may be vascular bed specific, we show that caspase-1 is involved, at least in part, in apoptosis of three types of EC: HUVEC, HSVEC, and MLEC. HUVEC and HSVEC represent large vessel ECs in humans, and the mouse preparation predominantly represents microvascular ECs. The importance of caspase-1 in apoptosis was further verified in differentiated EC lines. There was a substantial reduction of SW-induced apoptosis in the presence of z-YVAD in HSVEC, and similar results were also found in human lung microvascular ECs.

\section{Proinflammatory Caspase-1 Substrates}

Caspase-1 was originally identified as having a major role in processing IL-1 $\beta$ to its active form (Yuan et al, 1993) and later was found also to process IL-18 (Ghayur et al, 1997; Gu et al, 1997). We therefore investigated the activation status of these caspase-1 substrates in SW HUVEC and MLEC whole cell lysates. We were unable to demonstrate IL-1 $\beta$ processing by Western blot analysis. The effect of this cytokine upon apoptosis in other cell types is variable, depending on the cells examined and the conditions of the experimental protocol (Fratelli et al, 1995; Friedlander et al, 1996; Tatsuta et al, 1996). We have no evidence that IL-1 $\beta$ can itself modify the SW-induced effects in HUVEC, because we have not observed any alteration in rates of apoptosis with the addition of $\mathrm{IL}-1 \beta$ under basal conditions or SW (our unpublished results). We were unable to demonstrate either mature or processed IL-1 $\beta$ in SW cell lysates, despite caspase- 1 activation, and this may reflect the insensitivity of this type of analysis for the small amount of IL-1 $\beta$ present under these circumstances (Schonbeck et al, 1997). IL-1 $\beta$ synthesis is documented in ECs, but this often requires stimulation by inflammatory agents. We used early passage quiescent HUVEC, and it seems likely that these cells will have low production of IL-1. IL-1 $\beta$ release in its active form from ECs has proven difficult to document and has required the use of bioassays (Schumann et al, 1998). Similarly we were unable to document IL-18 in cultured HUVEC or MLEC, which is in agreement with others (Gerdes et al, 2002). Thus, we are unable to say whether SWinduced caspase- 1 activation could process IL-1 $\beta$ or IL-18; but certainly at the levels these cytokines are expressed, it seems unlikely that they cooperate mechanistically in SW-induced apoptosis in EC.

\section{SW-Induced Apoptosis and ROS}

To determine whether ROS production, induced by SW, might result in caspase- 1 activation, SW experi- ments were performed using the antioxidant NAC. NAC completely inhibited ROS production during 2 hours of SW; thereafter, ROS production remained at significantly lower levels than in untreated cells. This incomplete inhibition of ROS at later time points is probably a result of the depletion of exogenous NAC, because NAC is readily taken up by the cell, where it is converted to glutathione. Despite inhibiting ROS, NAC failed to have any inhibitory effects on SWinduced apoptosis, suggesting that the two processes are not mechanistically linked. Furthermore, ROS do not seem to be linked to caspase- 1 activation induced by SW.

\section{A Role for Caspase-1 in Apoptosis}

The study presented here clearly demonstrates a specific role for caspase-1 in EC SW-induced apoptosis. However, data from others indicate that caspase-3 activation is an important mechanism in HUVEC SW-induced apoptosis (Levkau et al, 1998) and apoptosis induced by proteosome inhibitors (Drexler et al, 2000). It seems likely therefore that caspase-1 acts as an upstream caspase in SWinduced apoptosis that could interact with a number of executioner caspases, including caspase-3 but also possibly caspase-7 (Marsden et al, 2002). We detected abundant levels of caspase- 3 proenzyme that were unchanged with SW, but we were unable to detect processing of this enzyme by Western blot analysis of whole cell extracts. In our hands, using whole cell extracts, we have found it difficult to demonstrate caspase- 3 cleavage and activation. This may arise because caspase- 3 activation occurs close to the time of cell detachment in EC apoptosis.

The mechanisms involved in the activation of caspase-1 in response to SW remain elusive. Recently, the inflammasome has been described (Martinon et al, 2002), a caspase-activating complex comprising caspase-1, caspase-5, Pycard, and NALP1 that is linked to IL-1 $\beta$ processing. Pycard seems to be essential for caspase-1 activation. The inflammasome complex was described in an in vitro system (Martinon et al, 2002). It remains to be determined whether such complex interactions could be demonstrated or are indeed essential in our SW model. Another important route to caspase activation has been shown to proceed via assembly of the apoptosome as a result of the cell stress-associated release of mitochondrial cytochrome C (Li et al, 1997; Liu et al, 1996). Recruitment of several caspase- 9 molecules results in autoprocessing and activation of this caspase, which can then process additional downstream caspases (Slee et al, 1999). However, in this cell-free system, caspase- 1 failed to be activated under these conditions, so perhaps caspase- 1 is activated independently of the apoptosome as suggested by Marsden et al (2002).

\section{SW as a Stimulus for EC Apoptosis}

SW has been used as an initiator of EC apoptosis because of its reproducible effects and is an estab- 
lished technique for apoptosis induction in nontransformed cells. It is a model of growth factor withdrawal and is a reasonable method to use to examine the basic machinery of EC apoptosis because ECs are resistant to apoptosis in response to many death receptor-induced signals (Karsan et al, 1996; Richardson et al, 1994). The pathophysiologic correlate of SW-induced apoptosis is uncertain, although the exact mechanisms of EC apoptosis in the clinical situation are similarly uncertain and also may involve deprivation of survival signals.

\section{Summary}

These results give clear evidence that EC apoptosis, at least in response to SW, is significantly delayed in caspase $-1^{-/-}$mice and that it can be modulated with caspase inhibitors in HUVEC, indicating that caspase- 1 activation influences apoptosis in this cell type. It seems likely that caspase- 1 is acting as an upstream or regulatory/amplifier caspase. SWinduced cell death and caspase-1 activation are not dependent on ROS production. Although the precise mechanisms leading to caspase-1 activation are unclear, these results support a role for caspase-1 beyond cytokine processing in an important differentiated cell type.

\section{Materials and Methods}

\section{Primary MLEC Isolation}

Caspase-1 $1^{-1-}$ mice were a gift from Dr. W. Wong, BASF Bioresearch Corporation (Li et al, 1995). MLECs were prepared from wild-type (C57/B6) and caspase$1^{-/-}$mice using the method of Hartwell et al (1998) with some minor modifications. Briefly, three or more 12- to 14-week-old female mice were killed by cervical dislocation, and the heart and lungs were perfused in situ with PBS containing $18 \mathrm{U} / \mathrm{ml}$ sodium heparin/ PBS. Lung tissues were collected in and washed with Ham's F12 medium (Gibco). Lungs were dissected free of surplus connective tissue, briefly dipped in $70 \%$ ethanol to remove the mesothelium, and washed thoroughly before being minced into 1- to 2-mm pieces. The tissue was then digested with $20 \mathrm{ml}$ of freshly prepared $0.1 \%$ collagenase I (Worthington Biochemicals; batch number M7D1138) at $37^{\circ} \mathrm{C}$ for 1 hour. The cellular digest was filtered through a $40-\mu \mathrm{m}$ wire mesh (Bellco Glass Inc.) and centrifuged at 100 $\times g$ for 10 minutes at $4^{\circ} \mathrm{C}$; the pellet was resuspended in $10 \mathrm{ml}$ of CGM and plated on $0.1 \%$ gelatin-coated flasks. Twelve to 24 hours later, the plates were washed with warm PBS and fresh CGM was added. Dynabeads coated with sheep anti-rat IgG (Dynal, Wirral, United Kingdom) were incubated with rat antimouse Fc $\gamma$ III/II receptor or intercellular adhesion molecule-2 (ICAM-2) IgG (PharMingen) at $4^{\circ} \mathrm{C}$ overnight, washed three times with $2 \%$ FCS in PBS. The FC $\gamma$ III/II receptor-coated (negative sorts) or ICAM-2coated (positive sorts) beads were then added to the plated cells, which had been precooled to $4^{\circ} \mathrm{C}$ for at least 30 minutes. After 1 hour of incubation at $4^{\circ} \mathrm{C}$, the plates were washed with PBS and trypsinized to collect the cells. Cells not bound to the beads (negative sort to remove macrophages) or bound (ICAM-2 positive) were recovered using a magnetic field, washed, and plated on $0.1 \%$ gelatin-coated flasks. Cells were subjected to one negative and two positive bead sorts before being used in FACS or TLVM experiments. For TLVM, confluent caspase- $1^{-1-}$ and wild-type MLEC were washed several times with PBS and incubated in base media without serum for 48 hours. Filming commenced after gassing in $95 \%$ air/5\% $\mathrm{CO}_{2}$ for 1 hour as described above.

\section{Flow Cytometry of MLECs}

MLEC were stimulated with $20 \mathrm{ng} / \mathrm{ml}$ mouse TNF- $\alpha$ (R\&D Systems) for 4 hours. Cells were trypsinized according to standard protocols, washed, and incubated with rat anti-mouse E-selectin IgG (PharMingen) at 1:100 dilution for 30 minutes at $4^{\circ} \mathrm{C}$. Cells were then incubated with FITC-labeled goat anti-rat lgG (Biosource International, Camarillo, California) at 1:200 dilution for 30 minutes at $4^{\circ} \mathrm{C}$. Cells were fixed in $1 \%$ formaldehyde, and the fluorescence of 5000 cells was assessed by flow cytometry.

\section{Induction of SW-Induced Apoptosis}

For SW, $80 \%$ confluent monolayers were washed five times in serum-free M199 before incubation with M199. Controls were treated in the same way before replacing with fresh CGM.

\section{$T L V M$}

Flasks were gassed for 1 hour at $37^{\circ} \mathrm{C}$ in a $95 \%$ air $/ 5 \% \mathrm{CO}_{2}$ atmosphere, tightly sealed, and filmed on inverted microscopes at $37^{\circ} \mathrm{C}$ with video synchronization (EOS, Barry, United Kingdom). Apoptotic cell death events were scored when the cell became rounded up and detached. Each culture was analyzed in duplicate.

\section{HUVEC Cell Culture}

HUVEC were isolated as described previously (Jaffe et al, 1973) and cultured in M199 $+20 \mu \mathrm{g} / \mathrm{ml}$ endothelial growth supplement $+90 \mu \mathrm{g} / \mathrm{ml}$ heparin $+10 \%$ FCS + $10 \%$ NBCS CGM. HUVEC were used at first or second passage and induced to undergo apoptosis as described above.

\section{HSVEC and HMEC Culture}

HSVEC were obtained from Cambrex-Biowhittiker and cultured following the manufacturer's protocol in specific culture medium. Human lung microvascular ECs were obtained from in-house sources and cultured as for HUVEC.

\section{DNA Fragmentation Analysis}

After HUVEC SW, the detached, floating cells in the culture medium were collected by centrifugation. DNA 
was isolated according to the manufacturer's instructions using a Calbiochem Suicide-Track kit. Isolated DNA pellets were subjected to agarose gel electrophoresis and ethidium bromide staining.

\section{SW Rescue Experiments}

HUVEC were induced to undergo apoptosis as described above and preincubated for 6 hours at $37^{\circ} \mathrm{C}$ in a $95 \%$ air $/ 5 \% \mathrm{CO}_{2}$ atmosphere. Cells were then either left untreated or treated with IGF-I (100 ng/ml), bFGF (100 ng/ml), ECGS (20 $\mu \mathrm{g} / \mathrm{ml})$, or CGM components (10\% FCS, 10\% NBCS, $90 \mu \mathrm{g} / \mathrm{ml}$ heparin, 20 $\mu \mathrm{g} / \mathrm{ml}$ ECGS) and filmed for 48 hours. Apoptosis was quantified by TLVM analysis. Control cells were incubated in CGM for both the 6-hour preincubation and the 48-hour TLVM.

\section{Protein Isolation and Assay}

MLEC and HUVEC monolayers were washed in PBS at the end of SW. Cells were scraped into ice-cold RIPA lysis buffer (1\% NP-40, 0.5\% sodium deoxycholate, $0.1 \%$ SDS, PBS) with freshly added protease inhibitors (10 $\mu \mathrm{g} / \mathrm{ml}$ phenylmethylsulfonyl fluoride, 5 $\mu \mathrm{g} / \mathrm{ml}$ aprotinin, $5 \mu \mathrm{g} / \mathrm{ml}$ leupeptin) and incubated on ice for 30 minutes. Whole cell lysates were centrifuged for 20 minutes at $4^{\circ} \mathrm{C}$, and the supernatant was transferred to a fresh tube. Protein concentration was determined using a Micro BCA protein assay kit (Pierce) following the manufacturer's instructions. Before SDSPAGE electrophoresis, 25 to $50 \mu \mathrm{g}$ of protein was mixed with an equal volume of $\beta$-mercaptoethanol-containing sample buffer and boiled for 2 minutes.

\section{Western Blot Analysis}

After SDS-PAGE electrophoresis, proteins were blocked onto a nitrocellulose membrane and blocked in $5 \%$ nonfat dried milk in TBS overnight at $4^{\circ} \mathrm{C}$. Primary antibodies were used at the following concentrations: caspase-1 p45, 1:200 (Santa Cruz); caspase-1 p20, $1 \mu \mathrm{g} / \mathrm{ml}$ (Biosource); caspase-3, 1:10 000 (Merck); IL-1 $\beta, 1: 100$ (Santa Cruz); and IL-18, 1:100 (Santa Cruz), for 1 hour at room temperature. Secondary antibodies were horseradish peroxidaseconjugates (Dako) diluted 1:1000 and incubated for 1 hour at room temperature. Membranes were washed in TBS-0.05\% Tween-20 and proteins were detected by ECL. Membranes were subsequently stripped and hybridized with an actin control antibody diluted 1:100 (Santa Cruz).

\section{Caspase Inhibitors}

z-VAD-FMK, an irreversible, cell permeable nonspecific caspase inhibitor, was obtained from Enzyme System Products. Z-YVAD-CHO, a reversible, cellpermeable caspase-1 inhibitor, was obtained from Research Biochemical International. Caspase inhibitors were added at the start of SW.

\section{Antioxidants}

NAC (Sigma) was dissolved in PBS and added to M199 or CGM at $25 \mathrm{~mm}$. The $\mathrm{pH}$ of the NAC-containing medium was adjusted to within optimum range, sterile filtered, and added to HUVEC at the start of SW.

\section{Fluorogenic Caspase Assays}

Cell extracts were prepared as previously described (Enari et al, 1996). Fifty to $60 \mu \mathrm{g}$ of protein was used for each sample in a final volume of $1 \mathrm{ml}$. The fluorogenic caspase-1 substrate MCA-YVADAPK-dnp (Bachem, United Kingdom) was added to a final concentration of $1 \mu \mathrm{mol} / \mathrm{L}$, and the samples were read at excitation $325 \mathrm{~nm}$ and emission $392 \mathrm{~nm}$. For other experiments, caspase- 1 activity was measured using a Promega Fluorometric CaspACE assay system and a micro-plate format, using Ac-YVAD-AMC as a substrate for each assay following the manufacturer's instructions.

\section{Caspase-1 Transfection in HUVEC and HeLa}

HUVEC were purchased from TCS and grown to passage 2. HeLa were obtained from in-house sources. Caspase 1 was obtained in the vector pSP73 and cloned into pEGFP-C1 (pEGFP.caspase-1). Transfections were performed in Optimem (Gibco$\mathrm{BRL}$ ) for 2 hours using $0.5 \mu \mathrm{g}$ of DNA and a ratio of $2: 1$ with Tfx-50 (Promega), according to the manufacturer's instructions. After transfection, the DNA:lipid mixture was removed and cells were fed with 1:1 fresh complete medium:24-hour conditioned growth medium. HUVEC cell death was assessed by morphology (small condensed cells) in transfected cells identified by the presence of GFP using fluorescence microscopy. Death was recorded at 48 hours after transfection. HeLa protein was isolated as described above 48 hours after transfection.

\section{ROS Measurement}

ROS production was detected using the dye $2^{\prime}, 7^{\prime}-$ dichlorofluorescin diacetate (DCF-DA; Molecular Probes), a nonfluorescent cell-permeable compound. Once inside the cell, it is de-esterified by endogenous esterases and oxidized by ROS to become the fluorescent compound DCF (2',7'-dichlorofluorescein). The DCF fluorescence reflects the amount of ROS present in the cells at the time of dissociation (Bass et al, 1983; LeBel et al, 1992). HUVEC were induced to undergo SW as described above in the presence or absence of $25 \mathrm{~mm}$ NAC. During the last hour of SW, 10 $\mu \mathrm{M}$ DCF-DA was added to the cells. Control cultures (CGM) were also incubated with DCF-DA for 1 hour. Cells were harvested by trypsinization, washed once in PBS $+2 \%$ FCS, and resuspended in $1 \mathrm{ml}$ of PBS + $2 \%$ FCS. Data were collected with a FACScan fluorescence accelerated cell scanner using the data acquisition program CellQuest (Becton Dickinson). DCF data were collected at an excitation wavelength of $475 \mathrm{~nm}$ and an emission wavelength of $525 \mathrm{~nm}$. A 
total of 10,000 live cells were analyzed per sample. The mean DCF fluorescence of each histogram was calculated as an indication of ROS production.

\section{Statistics}

Values are stated as means \pm SEM. Statistical comparison used the Student's $t$ test.

\section{References}

Araki S, Ishida T, Yamamotom T, Kaji K, and Hayash $\mathrm{H}$ (1993). Induction of apoptosis by hemorrhagic snake venom in vascular endothelial cells. Biochem Biophys Res Commun 190:148-153.

Bass DA, Parce JW, Dechatelet LR, Szejda P, Seeds MC, and Thomas M (1983). Flow cytometric studies of oxidative product formation by neutrophils: A graded response to membrane stimulation. J Immunol 130:1910-1917.

Bordron A, Dueymes M, Levy Y, Jamin J, Lero J-P, Piette J-C, Shoenfeld Y, and Youinou PY (1998). The binding of some human anti-endothelial cell antibodies induces endothelial cell apoptosis. J Clin Invest 101:2029-2035.

Cerretti DP, Kozlosky CJ, Mosley B, Nelson N, Van Ness K, Greenstreet TA, March CJ, Kronheim SR, Druck T, Cannizzaro LA, Huebner K, and Black RA (1992). Molecular cloning of the interleukin- $1 \beta$ converting enzyme. Science 256:97-99.

Chen $\mathrm{C}-\mathrm{H}$, Jiang $\mathrm{T}$, Yang J-H, Jiang $\mathrm{W}$, Lu J, Marathe GK, Pownall HJ, Ballantyne CM, McIntyre TM, Henry PD, and Yang C-Y (2003). Low-density lipoprotein in hypercholesterolemic human plasma induces vascular endothelial cell apoptosis by inhibiting fibroblast growth factor 2 transcription. Circulation 107:2102-2108.

Choi KB, Wong F, Harlan JM, Chaudhary PM, Hood L, and Karsan A (1998). Lipopolysaccharide mediates endothelial apoptosis by a FADD-dependent pathway. J Biol Chem 273:20185-20188.

Dai C and Krantz SB (1999). Interferon gamma induces upregulation and activation of caspases 1,3 , and 8 to produce apoptosis in human erythroid progenitor cells. Blood 93:3309-3316.

Dunham BP and Koch RJ (1998). Basic fibroblast growth factor and insulin-like growth factor I support the growth of human septal chondrocytes in a serum-free environment. Arch Otolaryngol Head Neck Surg 124:1325-1230.

Drexler HC, Risau W, and Konerding MA (2000). Inhibition of proteosome function induces programmed cell death in proliferating endothelial cells. FASEB J 14:65-77.

Enari M, Talanian RV, Wong WW, and Nagata S (1996). Sequential activation of ICE-like and CPP32-like proteases during Fas-mediated apoptosis. Nature 380:723-726.

Fratelli M, Gagliardini V, Galli G, Gnocchi P, and Ghezzi P (1995). Autocrine interleukin $1 \beta$ regulates both proliferation and apoptosis in EL4-6.1 thymoma cells. Blood 85:3532-3537.

Friedlander RM, Gagliardini V, Rotello RJ, and Yuan J (1996). Functional role of interleukin $1 \beta$ (IL-1 $\beta)$ in IL-1 $\beta$-converting enzyme-mediated apoptosis. J Exp Med 184:717-724.

Garcia-Calvo M, Peterson EP, Leitin B, Ruel R, Nicholson DW, and Thornberry NA (1998). Inhibition of human caspases by peptide-based and macromolecular inhibitors. J Biol Chem 273:32608-32613.
Gerdes N, Sukhova GK, Libby P, Reynolds RS, Young JL, and Schonbeck $U$ (2002). Expression of interleukin (IL)-18 and functional IL-18 receptor on human vascular endothelial cells, smooth muscle cells and macrophages: Implications for atherogenesis. J Exp Med 195:245-257.

Ghayur T, Banerjee S, Hugunin M, Butler D, Herzog L, Carter A, Quintal L, Sekut L, Talanian R, Paskind M, Wong W, Kamen R, Tracey D, and Allen H (1997). Caspase-1 processes IFN- $\gamma$-inducing factor and regulates LPS-induced IFN- $\gamma$ production. Nature 386:619-623.

Greenlund LJS, Deckwerth TL, and Johnson EM (1995). Superoxide dismutase delays neuronal apoptosis: A role for reactive oxygen species in programmed cell death. Neuron 14:303-315.

Gu Y, Kuida K, Tsutsui H, Ku G, Hsiao K, Fleming MA, Hayashi N, Higashino K, Okamura H, Nakanishi K, Kurimoto M, Tanimoto T, Flavell RA, Sato V, Harding MW, Livingston DJ, and Su MS-S (1997). Activation of interferon- $\gamma$ inducing factor mediated by interleukin- $1 \beta$ converting enzyme. Science 275:206-207.

Haimovitz-Freidman A, Kan CC, Ehleiter D, Persavd RS, McLoughlin M, Fuks Z, and Kolesnik RN (1994). Ionizing radiation acts on cellular membranes to generate ceramide and initiate apoptosis. J Exp Med 180:525-535.

Harada-Shiba M, Kionoshita M, Kamido H, and Shimokado K (1998). Oxidized low density lipoprotein induces apoptosis in cultured human umbilical vein endothelial cells by common and unique mechanisms. J Biol Chem 273:9681-9687.

Hartwell DW, Mayadas TN, Berger G, Frenette PB, Rayburn H, Hynes RO, and Wagner DD (1998). Role of P-selectin cytoplasmic domain in granular targeting in vivo and in early inflammatory responses. J Cell Biol 143:1129-1141.

Hersh D, Monack DM, Smith MR, Ghori N, Falkow S, and Zychlinsky A (1999). The Salmonella invasin SipB induces macrophage apoptosis by binding to caspase- 1 . Proc Natl Acad Sci USA 96:2396-2401.

Hilbi H, Moss JE, Hersh D, Chen Y, Arondel J, Banerjee S, Flavell RA, Yuan J, Sansonetti PJ, and Zychlinsky A (1998). Shigella-induced apoptosis is dependent on caspase-1 which binds to IpaB. J Biol Chem 273:32895-32900.

Jacobson MD, Weil M, and Raff MC (1996). Role of Ced-2/ ICE family proteases in staurosporine-induced programmed cell death. J Cell Biol 133:1041-1051.

Jaffe EA, Nachman RL, Becker GC, and Minick CR (1973). Culture of human endothelial cells derived from umbilical veins: Identification by morphologic and immunologic criteria. J Clin Invest 52:2744-2745.

Karsan A, Yee E, and Harlan JM (1996). Endothelial cell death induced by tumor necrosis factor-alpha is inhibited by the Bcl-2 family member, A1. J Biol Chem 271:27201-27204.

Kuida K, Lippke JA, Ku G, Harding MW, Livingston DJ, Su MS-S, and Flavell RA (1995). Altered cytokine export and apoptosis in mice deficient in interleukin- $1 \beta$ converting enzyme. Science 267:2000-2002.

Kuida K, Zheng TS, Na S, Kuan C-Y, Yang D, Karasuyama H, Rakic P, and Flavell RA (1996). Decreased apoptosis in the brain and premature lethality in CPP32-deficient mice. Nature 384:368-375.

Laurence J, Mitra D, Steiner M, Staiano-Coico L, and Jaffe E (1996). Plasma from patients with idiopathic and human immunodeficiency virus-associated thrombotic thrombocy- 
topenic purpura induces apoptosis in microvascular endothelial cells. Blood 87:3245-3254.

LeBel CP, Ischiropoulos H, and Bondy SC (1992). Evaluation of the probe $2^{\prime}, 7^{\prime}$-dichlorofluorescin as an indicator of reactive species formation and oxidative stress. Chem Res Toxicol 5:227-231.

Levkau B, Koyama H, Raines EW, Clurman BE, Herren B, Orth K, Roberts JM, and Ross R (1998). Cleavage of p21(Cip1/Waf1) and p27(Kip1) mediates apoptosis in endothelial cells through activation of Cdk2: Role of a caspase cascade. Mol Cell 1:553-563.

Li P, Allen H, Banerjee S, Franklin S, Herzog L, Johnston C, McDowell J, Paskind M, Rodman L, Salfeld J, Towne E, Tracey D, Wardwell S, Wei F-Y, Wong W, Kamen R, and Seshadri T (1995). Mice deficient in IL-1 $\beta$ converting enzyme are defective in production of mature IL-1 $\beta$ and resistant to endotoxic shock. Cell 80:401-411.

Li P, Nijhawan D, Budihardjo I, Srinvasula SM, Ahmad M, Alnemri ES, and Wang X (1997). Cytochrome c and dATPdependent formation of Apaf-1/caspase-9 complex initiates an apoptotic protease cascade. Cell 91:479-489.

Lin XY, Choi MSK, and Porter AG (2000). Expression analysis of the human caspase- 1 subfamily reveals specific regulation of the CASP5 gene by lipopolysaccharide and interferon- $\gamma$. J Biol Chem 275:39920-39926.

Liu X, Kim CN, Yang J, Jemmerson R, and Wang X (1996). Induction of apoptotic program in cell-free extracts: Requirement for dATP and cytochrome c. Cell 86:147-157.

Margolin N, Raybuck SA, Wilson KP, Chen W, Fox T, Gu Y, and Livingston DJ (1997). Substrate and inhibitor specificity of interleukin- $1 \beta$-converting enzyme and related caspases. J Biol Chem 272:7223-7228.

Marsden VS, O'Connor L, O'Reilly LA, Silke J, Metcalf D, Ekert PG, Huang DCS, Cecconi F, Kuida K, Tomaselli KJ, Roy S, Nicholson DW, Vaux DL, Bouillet P, Adams JM, and Strasser A (2002). Apoptosis initiated by $\mathrm{Bcl}-2$ regulated caspase activation independently of the cytochrome c/Apaf1/caspase-9 apoptosome. Nature 419:634-637.

Martinon F, Burns K, and Tschopp J (2002). The inflammasome: A molecular platform triggering activation of inflammatory caspases and processing of pro-IL-1 $\beta$. Mol Cell 10:417-426.

McCarthy NJ, Whyte MK, Gilbert CS, and Evan GI (1997). Inhibition of Ced-3/ICE-related proteases does not prevent cell death induced by oncogenes, DNA damage, or the Bcl-2 homologue Bak. J Cell Biol 136:215-227.

Miura M, Zhu H, Rotello R, Hartwig EA, and Yuan JY (1993). Induction of apoptosis in fibroblasts by IL-1-beta-converting enzyme, a mammalian homolog of the c-elegans cell-death gene ced-3. Cell 75:653-660.

Nicholson DW and Thornberry NA (1997). Caspases: Killer proteases. Trends Biochem Sci 22:299-306.

Ona VO, Li MW, Vonsattel JPG, Andrews LJ, Khan SQ, Chung WM, Frey AS, Menon AS, Li X-J, Steig PE, Yuan J, Penney JB, Young $\mathrm{AB}$, Cha $\mathrm{J}-\mathrm{HH}$, and Friedlander RM (1999). Inhibition of caspase-1 slows disease progression in a mouse model of Huntington's disease. Nature 399:263267.

Polunovsky VA, Wendt CH, and Ingbar DH (1994). Induction of endothelial cell death by TNF- $\alpha$ : Modulation by inhibitors of protein synthesis. Exp Cell Res 214:584-594.
Richardson BC, Lalwani ND, Johnson KJ, and Marks RM (1994). Fas ligation triggers macrophages but not endothelial cells. Eur J Immunol 24:2640-2645.

Rowe SJ, Allen L, Ridger VC, Hellewell PG, and Whyte MK (2002). Caspase-1-deficient mice have delayed neutrophil apoptosis and a prolonged inflammatory response to lipopolysaccharide-induced acute lung injury. J Immunol 169:6401-6407.

Saltau JB and McLaughlin BJ (1993). Effects of growth factors on wound healing in serum-deprived kitten corneal endothelial cell cultures. Cornea 12:208-215.

Sata M and Walsh K (1998). Oxidized LDL activates Fasmediated endothelial cell apoptosis. J Clin Invest 102:16821689.

Schonbeck U, Mach F, Bonnefoy J-Y, Loppnow H, Flad H-D, and Libby $P$ (1997). Ligation of CD40 activates interleukin $1 \beta$ converting enzyme (caspase-1) activity in vascular smooth muscle and endothelial cells and promotes elaboration of active interleukin 1 $\beta$. J Biol Chem 272:19569-19574.

Schreck R, Rieber P, and Baeuerle PA (1991). Reactive oxygen intermediates as apparently widely used messengers in the activation of NF- $\kappa \mathrm{B}$ transcription factor and HIV 1. EMBO J 10:2247-2258.

Schumann RR, Belka C, Reuter D, Lamping N, Kirschning CJ, Weber JR, and Pfeil D (1998). Lipopolysaccharide activates caspase-1 (interleukin-1-converting enzyme) in cultured monocytic and endothelial cells. Blood 91:577-584.

Sgonc R, Gruschwitz MS, Dietrich H, Recheis H, Gershwin ME, and Wick G (1996). Endothelial cell apoptosis is a primary pathogenetic event underlying skin lesions in avian and human scleroderma. J Clin Invest 98:785-792.

Slater AFG, Stefan C, Nobel I, van den Dobblesteen DJ, and Orrenius S (1996). Signaling mechanisms and oxidative stress in apoptosis. Toxicol Lett 82- 83:149-153.

Slee EA, Harte MT, Kluck RM, Wolf BB, Casiano CA, Newmeyer DD, Wang H-G, Reed JC, Nicholson DW, Alnemri ES, Green DR, and Martin SJ (1999). Ordering the cytochrome c-initiated caspase cascade: Hierarchical activation of caspases-2, -3, -6, -7, -8 and -10 in a caspase-9-dependent manner. J Cell Biol 144:281-292.

Suzuki YS, Forman HJ, and Sevanian A (1997). Oxidants as stimulators of signal transduction. Free Radic Biol Med 22:269-285.

Tatsuta T, Cheng J, and Mountz JD (1996). Intracellular IL-1 $\beta$ is an inhibitor of Fas-mediated apoptosis. J Immunol 157: 3949-3957.

Tricot O, Mallat Z, Heymes C, Belmin J, Leseche G, and Tedgui A (2000). Relation between endothelial cell apoptosis and blood flow direction in human atherosclerotic plaques. Circulation 101:2450-2453.

Whyte M (1996). ICE/CED-3 proteases in apoptosis. Trends Cell Biol 6:245-248.

Wolf BB and Green DR (1999). Suicidal tendencies: Apoptotic cell death by caspase family proteinases. J Biol Chem 274:20049-20052.

Yuan JY, Shaham S, Ledoux S, Ellis HM, and Horvitz HR (1993). The C. elegans cell death gene ced-3 encodes a protein similar to mammalian interleukin-1-beta-converting enzyme. Cell 75:641-652. 